\title{
Începuturile lexicografiei poloneze: care este modalitatea de prezentare a gloselor din dicționarul medieval în epoca digitală ? ${ }^{\dagger}$
}

\author{
Katarzyna Jasińska ${ }^{\oplus \star \Delta \star}$ \\ Institutul de Limbă Poloneză, Academia Poloneză de Științe, Al. Mickiewicza 31, 31-120 Cracovia, Polonia
}

\begin{abstract}
Despre articol
Istoric:

Primit 17 septembrie 2021

Acceptat 5 octombrie 2021

Publicat 12 decembrie 2021

Cuvinte-cheie:

diacronie

glose

editarea textelor

Rezumat

Obiectivul prezentului studiu este de a ilustra modul în care acest tip specific de atestare - glosele poloneze din dicționarele latine-poate fi ilustrat în format electronic. Punctul de plecare al analizei noastre îl constituie baza de date online Rozariusze z polskimi glosami (Rosarii cu glose poloneze - rozariusze.jpp.pan.pl). Baza de date este constituită din elemente de vocabular polonez utilizat în așanumitele rosarii, adică texte care reprezintă redacția poloneză a dicționarului Vocabularius Ex quo. Instrumentul online permite utilizatorilor să vizualizeze și să caute resursele grupate în următoarele categorii: atestări, intrări, concordanțe. Această bază de date a fost creată pentru a colecta informații despre elaborarea gloselor poloneze din aşa-numitele rosarii, dar poate fi o sursă de inspirație sau un model parțial pentru cercetări similare asupra acestui tip de atestări şi în alte limbi vernaculare.
\end{abstract}

\section{Introducere}

Printre marile lucrări lexicografice latine din perioada medievală care au ajuns pe teritoriul Poloniei în secolele al XIV-lea și al XV-lea se numără și dicționarul intitulat Vocabularius Ex quo, de origine germană. Acest dicționar este o compilație de alte texte de natură enciclopedică precum Elementarium doctrine erudimentum (de la mijlocul secolului al XI-lea) elaborat de Papias, Magna derivationes (sfîrșitul secolului al XII-lea) de Huguccio din Pisa, Catholicon de Johannes din Genova (1286) și Brevilogus (sfîrșitul secolului al XIV-lea) ${ }^{1}$. Vocabularius Ex quo (secolele al XIV-lea / al XV-lea) include informații semantice și gramaticale și, pe lîngă acestea, echivalenții germani ai lemelor latine (Grübmuller, 1990, p. 2040-2041).

În Polonia, dicționarul a fost adaptat nevoilor utilizatorilor locali. Deoarece a fost modificat aici, putem vorbi de fapt de o redacție poloneză a Vocabularius Ex quo. Există mai multe diferențe între versiunea tipică a Vocabularius Ex quo şi versiunea poloneză² : un incipit extins, un final elaborat, modificări în ceea ce privește aspectul și un sistem de simboluri gramaticale modificat față de cel utilizat în versiunea originală, omiterea traducerii germane a cuvintelor latinești și adăugarea de glose poloneze, definiții extinse cu informații semantice suplimentare și intrări adăugate sau omise (Jasińska et al., 2019, p. 148-160).

Dicționarele care aparțin redacției poloneze ${ }^{3}$ a Vocabularius Ex quo sînt cunoscute sub denumirea de rosarii (sing. rosarius). Numele vine de la un fragment al incipitului în care sînt prezentate caracteristicile lucrării: „Rosarius propter sui decorum”. Glosele poloneze care apar în dicționarele de acest gen au făcut

\footnotetext{
${ }^{\dagger}$ Proiectul intitulat „Vocabularul polonez din dicționarele latine ale secolului al XV-lea numite rosarii: Studiu comparativ”, director de proiect: prof. Ewa Deptuchowa, finanțat de Centrul Național pentru Știință (decizie număr: 2016/21/B/HS2/01249), s-a derulat la Institutul de Limbă Poloneză a Academiei Poloneze de Științe în perioada $2017-2021$.

*Adresă de corespondență: katarzyna.jasinska@ijp.pan.pl.

${ }^{1}$ Pentru descrierea fiecăruia dintre aceste dicționare medievale, vezi Grübmuller (1967), Considine (2019), Deptuchowa et al. (2020).

${ }^{2}$ Pentru informații detaliate, vezi Jasińska et al. (2019).

${ }^{3}$ În ediția critică a Vocabularius Ex quo, Grübmuller (1988-2001, p. 113-116) distinge cinci manuscrise principale și o redacție tipărită a acestui dicționar. Redacția poloneză ar putea aparține grupului de manuscrise intitulate „redacție liberă”.
} 
Katarzyna Jasińska

recent subiectul unei investigații mai extinse. Rezultatele acestei cercetări ${ }^{4}$ se regăsesc în baza de date Rozariusze z polskimi glosami (Rosarii cu glose poloneze); abreviere: RPG.

\section{Baza de date $\mathbf{R P G}^{5}$}

Baza de date pe care o prezentăm conține material polonez din toate sursele textuale descrise în literatura de specialitate ca rosarii. Analiza a indicat că acestea aparțin de fapt unor tipuri diverse de dicționare (Deptuchowa et al., 2020, p. 21-31). Versiunea finală a aranjamentului surselor textuale este următoarea: 5 copii de rosarii: RozKap (1450), RozOss I (XV p. post.), RozOss II (1476, XV p. post), RozOss III (XV p. post), RozPaul (1440), 3 copii ale Brevilogus (sau redacția lui poloneză): WokJag (1448), WokPet I (XV p. post), WokRacz (1442), 8 copii de dicționare de tip neidentificat (probabil rosarii): WokPet II (XVp. post), WokPet III (XV I), WokPet IV (XV p. post), WokPet V (1462), WokPet VI (1473), WokPet VII (1463, XV ex.), WokPet VIII (1457), WokPet IX (1460), 1 copie a Vocabularius Ex quo incunabulum: WokLub (ed. 1490, glose cca 1500).

Instrumentul online permite utilizatorilor să vizualizeze și să caute resursele astfel colectate în 3 tipuri de afișări: intrări, atestări și concordanțe (descrise mai jos). În plus, informațiile referitoare la sursele textuale sînt redate într-o secțiune separată.

\subsection{Atestări}

Entitatea de bază în acest mod de afișare este glosa poloneză prezentată în transliterare. Atestările sînt listate în ordine alfabetică. După fiecare glosă este indicată o siglă a textului, care, de fapt, reprezintă un link activ către atestarea care conține glosa individuală.

Un exemplu de atestare este prezentat în Fig. 1. Cuvîntul-titlu al atestării este glosa în transliterare $\left(k l o s^{6}\right)$. Dedesubt, glosa se repetă, de această dată plasată în contextul latinesc complet (Arista... dicitur sumitas calami proprie klos). Cuvintul polonez este subliniat. Alături este redată indicația bibliografică. Aceasta este formată din: dată (XV p. post.), numele prescurtat al sursei textuale (RozOss II) și fila de manuscris $\left(22^{\mathrm{r}}\right)$.

Apoi este prezentată secțiunea cu informaţiile de bază. Glosele sînt culese sub forma unui dicționar de limbă poloneză și sub forma concordanței latinești; astfel, în această secțiune se găsesc trimiterile glosei către intrarea în polonă (Ktos) și intrarea în latină (Arista). Datorită acestei soluții-care are numeroase avantaje-utilizatorii pot observa de cîte ori și în ce formă textuală un anumit lexem este atestat în dicționarele investigate. Pe de altă parte, se poate observa și modul în care un cuvînt latin este tradus în polonă.

Sub secțiunea cu informații se găsește o fotografie a fragmentului de manuscris care conține atestarea. Prin apăsarea butonului galben „Pokaż lokalizację” se accesează localizarea atestării în manuscris (fila 22 ${ }^{\mathrm{r}}$, tip de glosă: internă, rînd nr. 18).

Dedesubt se află o secțiune gramaticală în care se furnizează informații despre partea de vorbire și caracteristicile sale gramaticale (substantiv, număr singular, caz nominativ, gen masculin). Ultima secțiune cuprinde comentariile.

\subsection{Intrări}

Entitatea de bază în acest mod de afişare este intrarea poloneză prezentată în transcriere. Intrările sînt listate în ordine alfabetică. După fiecare glosă este specificată partea de vorbire. Acest lucru este util în cazul omonimelor. Pe acea listă se regăsesc, de asemenea, și entitățile de referință. Cel mai adesea, acestea sînt variante fonetice ale intrării principale.

\footnotetext{
${ }^{4}$ Studiile au vizat aspecte paleografice, semantice, gramaticale și legate de traducere ale gloselor poloneze. Baza de date RPG conține elaborarea de atestări individuale. Pentru o descriere detaliată a rezultatelor cercetării, vezi, de asemenea, Deptuchowa et al. (2020), unde materialul lingvistic este prezentat în alt mod. Manuscrisul individual reprezintă punctul de plecare. Dincolo de descrierea sa, sînt prezentate rezumate ale studiilor asupra bazei latine și a gloselor poloneze înregistrate în dicționarul analizat.

${ }^{5}$ Vezi rozariusze.ijp.pan.pl.

's'spic de cereale'.
} 


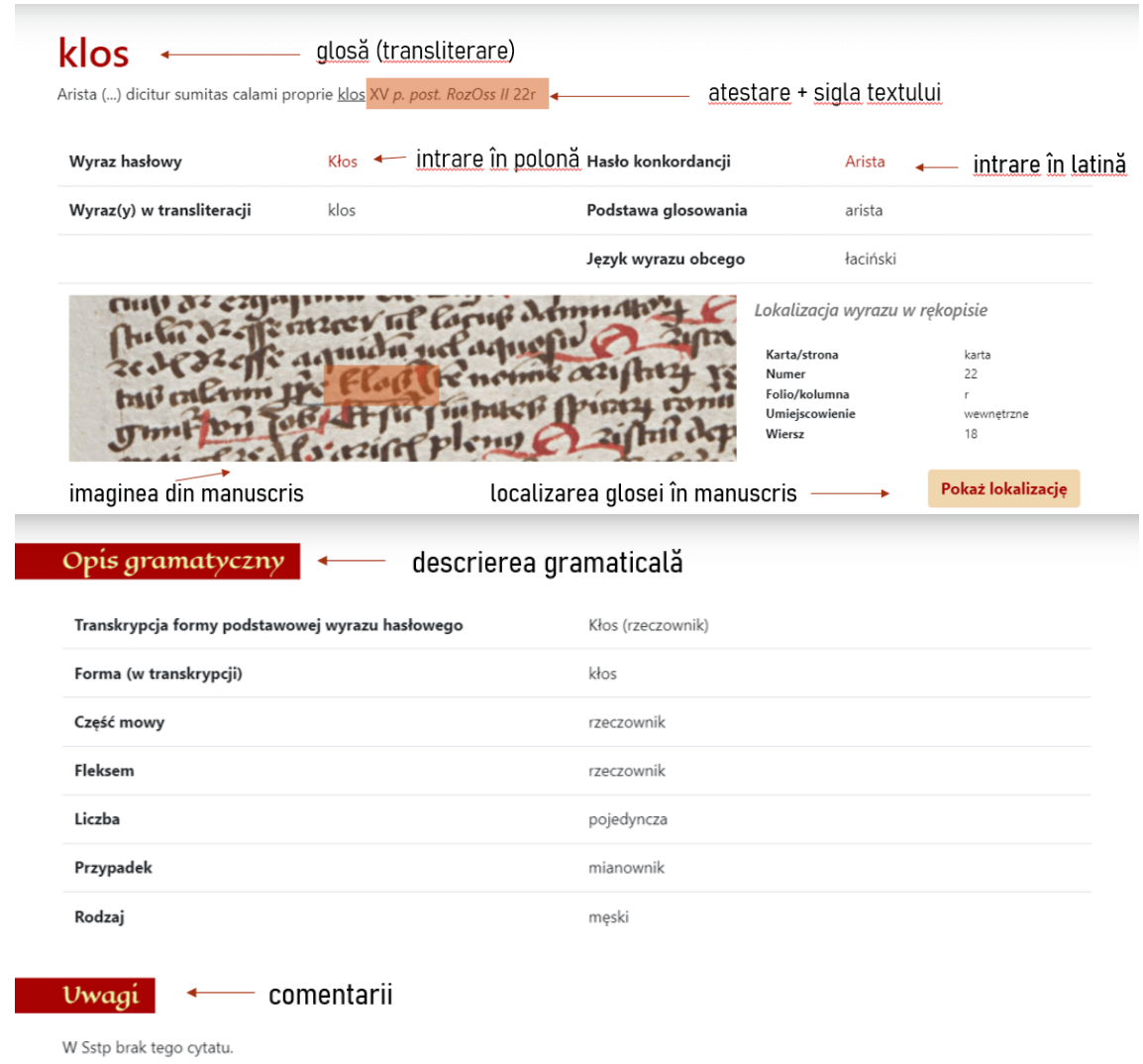

Figura 1: Atestarea klos în baza de date RPG

Kłos $\longrightarrow$ cuvint-titlu
rzeczownik $\longrightarrow$ parte de vorbire

\section{Formy gramatyczne $\longrightarrow$ lista formelor gramaticale}

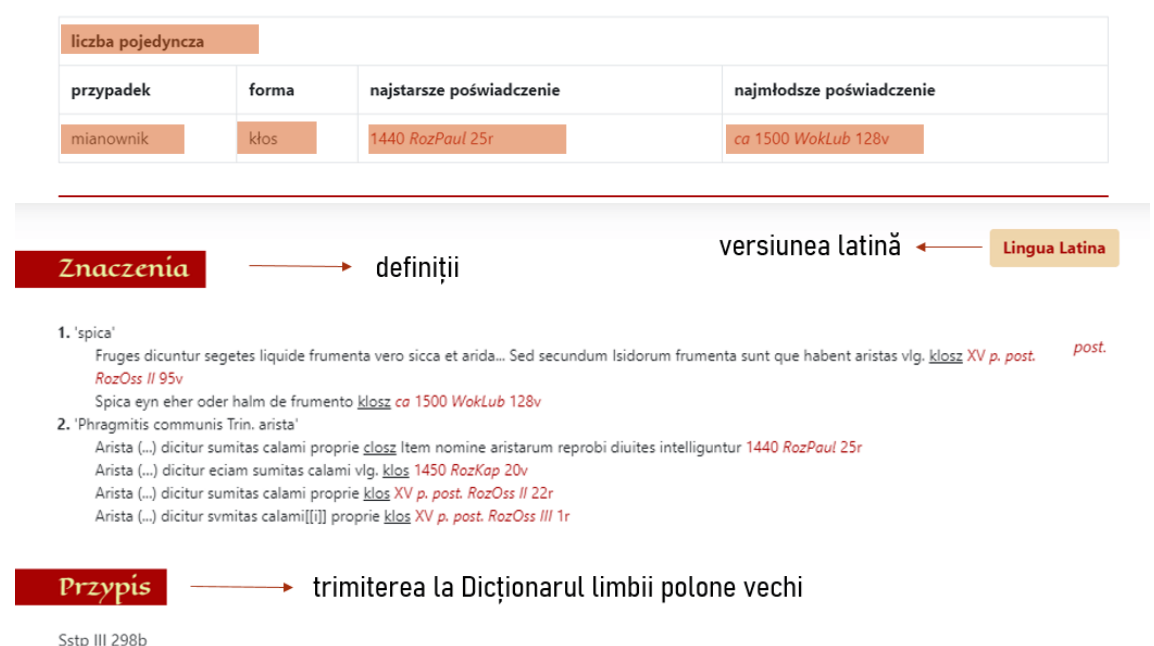

Figura 2: Intrarea poloneză Ktos în baza de date RPG

Un astfel de exemplu de intrare este prezentat în Fig. 2. Forma transcrisă a cuvîntului din limba poloneză veche este cuvîntul-titlu al intrării respective (Ktos). Sub aceasta se indică partea de vorbire și lista formelor gramaticale. Lista cuprinde descrierea gramaticală (număr singular, caz nominativ), urmată de forma transcrisă a cuvîntului (ktos) și indicarea celei mai vechi $\left(1440\right.$ RozPaul $\left.25^{\mathrm{r}}\right)$ și a celei mai recente (cca 1500 WokLub $128^{v}$ ) atestări textuale a intrării respective. 
Urmează prezentarea secțiunii semantice. În acea secțiune a intrării pot fi vizualizate toate atestările acesteia. Fiecare atestare care alcătuiește intrarea este asociată unei definiții particulare (1. 'inflorescență a unor ierburi sau cereale', 2. 'inflorescență a Phragmitis communis Trin.'). Indicația bibliografică este un link activ, astfel încît utilizatorii pot accesa cu ușurință acea atestare individuală. Apăsarea butonului galben „Lingua Latina” permite accesul la versiunea latină a definiției.

Sub secțiunea semantică se găsește și o trimitere la Dicționarul de limbă polonă veche (Urbańczyk, 1953-2002), cel mai mare dicționar al perioadei vechi a limbii polone (Sstp III 298b).

\subsection{Concordanțe}

Entitatea de bază în acest mod de afişare este intrarea latină. Intrările sînt afișate în ordine alfabetică. După cuvîntul-titlu în latină sînt redate echivalentele respectivului cuvînt în limba poloneză.

Ideea de concordanță latină se bazează pe prezentarea atestărilor care apar în intrările latine individuale. Acest lucru este posibil deoarece sursele textuale sînt formate din dicționare. Concordanțele reprezintă de fapt un tip de dicționar latin abstract, ideal, care include toate glosele poloneze din cuprinsul său.

Un astfel de exemplu de intrare este prezentat în Fig. 3. Cuvîntul-titlu al intrării-concordanță este cuvîntul în limba latină în forma sa medievală (Arista). Alături, este indicată lista tuturor surselor textuale în funcție de cronologia lor. Lista include numele numele prescurtate ale surselor textuale (RozPaul, WokRacz, WokJag, RozKap, WokPet VIII, WokPet IX, WokPet V, WokPet VII, WokPet VI, RozOss II, RozOss III, RozOss I, WokPet I, WokPet II, WokPet III, WokPet IV, WokLub). Dacă glosa poloneză apare într-o astfel de intrare latină din textul-sursă, aceasta este vizibilă lîngă numele prescurtat al sursei (RozPaul, RozKap, RozOss II, RozOss III). Glosa poloneză evidențiată este un link activ, astfel încît utilizatorii pot accesa cu ușurință respectiva atestare.

\begin{tabular}{|c|c|}
\hline Arista & $\longrightarrow$ cuvînt-titlu \\
\hline RozPaul & Arista (...) dicitur sumitas calami proprie closz Item nomine aristarum reprobi divites intelliguntur \\
\hline WokRacz & atestare \\
\hline WokJag & lista textelor-sursă \\
\hline RozKap & Arista (...) dicitur eciam sumitas calami vlg. klos \\
\hline \multicolumn{2}{|l|}{ WokPet VIII } \\
\hline \multicolumn{2}{|l|}{ WokPet IX } \\
\hline \multicolumn{2}{|l|}{ WokPet $V$} \\
\hline \multicolumn{2}{|l|}{ WokPet VII } \\
\hline \multicolumn{2}{|l|}{ WokPet VI } \\
\hline RozOss II & Arista (...) dicitur sumitas calami proprie klos \\
\hline RozOss III & Arista (...) dicitur svmitas calami[[i]] proprie klos \\
\hline \multicolumn{2}{|l|}{ RozOss I } \\
\hline \multicolumn{2}{|l|}{ WokPet I } \\
\hline \multicolumn{2}{|l|}{ WokPet II } \\
\hline \multicolumn{2}{|l|}{ WokPet III } \\
\hline \multicolumn{2}{|l|}{ WokPet IV } \\
\hline Woklub & \\
\hline
\end{tabular}

Figura 3: Intrarea latină Arista în baza de date RPG 


\subsection{Baza de date in cifre}

Materialul textual prezentat în baza de date include în total 6402 de atestări, 4197 intrări în poloneză, 3708 intrări în latină și 17 surse textuale.

O glosă este prezentată în trei moduri diferite în cadrul bazei de date. În primul rînd, se indică o descriere precisă a atestării, deci glosa poloneză în contextul în limba latină. Al doilea mod constă în redarea glosei ca parte a dicționarului polonez care include toate cuvintele care apar în sursele textuale. Cel de-al treilea mod constă în redarea glosei ca parte a unui dicționar abstract - concordanța latină.

\section{Concluzii}

Baza de date RPG reprezintă prima încercare de a prezenta cercetările asupra dicționarelor poloneze medievale în manieră modernă. Cîteva direcții posibile în care poate fi extinsă baza de date sînt: adăugarea de noi resurse textuale (rosarii), comparația cu alte tipuri de dicționare care conțin glose poloneze (Brevilogus, mammotrectus) și comparația cu surse textuale paralele care conțin glose în limbi vernaculare. În prezent nu este disponibilă versiunea în limba engleză a bazei de date, iar instrumentul nu este accesibil pentru utilizatorii externi.

$\mathrm{Cu}$ toate acestea, un obiectiv indirect al bazei de date a fost să atragem interesul altor cercetători, care să contribuie nu numai cu material textual, ci și cu metode de prezentare a gloselor în limbi vernaculare din dicționarele latine. Ne exprimăm speranța în posibilitatea îmbunătățirii acestui instrument online, care în viitorul apropiat ar putea deveni accesibil și altor cercetători.

\section{Bibliografie}

Considine, J. (2019). Medieval Latin Christendom, în Considine, J. (ed.), The Cambridge World History of Lexicography, Cambridge University Press, Cambridge, p. 267-289, Crossref.

Deptuchowa, E. et al. (eds) (2020). Rozariusze z polskimi glosami, Prace Instytutu Języka Polskiego PAN, Kraków.

Grübmuller, K. (1967). Vocabularius Ex quo. Untersuchungen zu lateinisch-deutschen Vokabularen des Spätmittelalters, C. H. Beck'sche Verlagsbuchhandlung, München.

Grübmuller, K. (ed.) (1988-2001). Vocabularius Ex quo. Überlieferungsgeschichtliche Ausgabe, vols. I-VI, Max Niemeyer Verlag, Tübingen.

Grübmuller, K. (1990). Die deutsche Lexikographie von den Anfängen bis zum Beginn des 17. Jahrunderts, în Hausmann, F.J. et al. (eds), Wörterbücher/Dictionaries/Dictionnaires (An International Encyclopedia of Lexicography), vol. II, Walter de Gruyter, Berlin, p. 2037-2049.

Jasińska, K. et al. (2019). Which Dictionary is Beautiful, Affluent and Concise at the Same Time? (in 15 ${ }^{\text {th }}$-century Poland), in Benati, Ch. \& Händl, C. (eds), From Glosses to Dictionaries: The Beginnings of Lexicography, Cambridge Scholars Publishing, Newcastle upon Tyne, p. 147-163.

RPG = Deptuchowa, E. et al. (eds) (2021). Rozariusze z polskimi glosami. Internetowa baza danych, IT Godny M., Kraków, online].

Urbańczyk, S. (ed.) (1953-2002). Stownik staropolski, vols. I-XI, Instytut Języka Polskiego Polskiej Akademii Nauk, Kraków. 